\title{
Analisis Kerusakan Bearing 7210 Pada Torsion Shaft
}

\author{
Kis Yoga Utomo ${ }^{1 *}$, Wismanto Setyadi², Pebri Ananda ${ }^{3}$ \\ ${ }^{1,3}$ Program Studi Teknik Mesin Fakultas Teknik Universitas Krisnadwipayana, Jl. Raya \\ Jatiwaringin, Pondok Gede, Jakarta Timur, Jakarta 13077. \\ ${ }^{2}$ Program Studi Teknik Mesin, Universitas Nasional, Jakarta 12520 \\ *Korespondensi penulis: yogautomo760@gmail.com
}

\begin{abstract}
Abstrak. Penelitian ini bertujuan untuk melakukan komparasi antara perhitungan teoritis dengan aktualisasi yang terjadi tentang bearing 7210 pada torsion shaft. Perbandingan yang dilakukan dilihat dari sisi umur pakai (lifetime) dari bearing tersebut dibandingkan dengan kondisi aktual yang terjadi. Selain itu analisa yang dilakukan adalah analisa yang berkaitan dengan proses relubrikasi serta analisa yang berkaitan dengan kuantitas grease yang diberikan pada saat proses relubrikasi. Perbedaan antara analisis teoritis dengan aktual disebut dengan deviasi. Perbedaan inilah yang akan dijadikan landasan untuk menyusun jadwal untuk melakukan proses pemeliharaan (preventive maintenance) yang difokuskan untuk memprediksi penggantian bearing dan proses relubrikasi yang dibutuhkan serta banyaknya pelumas yang digunakan. Hal ini bertujuan untuk meningkatkan lifetime bearing serta memperkecil deviasi yang terjadi antara perencanaan dan kondisi aktual di lapangan
\end{abstract}

Kata kunci: analisis kerusakan, bearing, penjadwalan perawatan, poros torsi.

\begin{abstract}
This study aims to compare the theoretical calculations with actualization that occur about 7210 bearings on the torsion shaft. Comparisons made are seen from the side of life (lifetime) of the bearing compared to the actual conditions that occur. In addition, the analysis carried out is an analysis relating to the process of relubication and analysis related to the quantity of grease given during the relubication process. The difference between theoretical analysis and actual is called deviation. This difference will be used as the basis for arranging a schedule for preventive maintenance that is focused on predicting the replacement of bearings and the required relubication process as well as the amount of lubricant used. This aims to increase lifetime bearings and minimize the deviation that occurs between planning and actual conditions in the field.
\end{abstract}

Keywords: bearing, damage analysis, maintenance scheduling, torsion shaft

\section{PENDAHULUAN}

Analisa kegagalan ialah suatu komponen yang mengalami kegagalan yang disebabkan oleh beberapa faktor yang mempengaruhi kinerja suatu alat. Dalam dunia industry, komponen - komponen alat pastilah mengalami suatu kegagalan, baik itu karena umur masa pakai alat yang habis, komponen tersebut sudah tidak berfungsi sama sekali, komponen tersebut berfungsi tapi membahayakan ataupun karena sebab-sebab lainnya. Kegagalan yang terjadi pada komponen-komponen mesin itu sangat merugikan bagi suatu industri apabila komponen mesin yang mengalami kegagalan merupakan komponen mesin yang sangat penting bagi industri itu sendiri. Dalam suatu komponen mesin itu sendiri banyak terdapat elemen - elemen mesin, seperti poros, roda gigi, engkol, bearing dan elemen lainnya [1].

Bearing merupakan salah satu bagian dari elemen mesin yang memegang peranan cukup penting karena fungsi dari bearing yaitu untuk menumpu sebuah poros agar poros dapat berputar tanpa mengalami gesekan yang berlebihan. bearing banyak sekali ditemukan di dalam komponen - komponen mesin karena fungsi dari bearing ini sangat vital untuk 
mengurangi gesekan yang terjadi pada mesin. Bearing atau bantalan adalah komponen sebagai bearing untuk membantu mengurangi gesekan peralatan berputar pada poros/as, bearing atau bantalan ini biasanya berbentuk bulat. Bearing di mobil dipasang pada as roda dan ditempat - tempat yang berputar lainnya. Tujuan dari bearing mengurangi gesekan rotasi dan mendukung radial dan aksial beban. Karena fungsinya yang krusial, bearing membutuhkan pemeliharaan yang baik sehingga di dapatkan umur kerja yang panjang. Salah satu bentuk pemeliharaan bearing yang utama adalah lubrikasi atau pelumasan. Analisis yang dilakukan berdasarkan perhitungan teoritis terhadap standar lifetime bearing untuk dikomparasikan dengan aktual yang terjadi pada saat penggunaan bearing 7210 pada unit torsion shaft. Analisis preventive maintenance yang dilakukan dengan perhitungan teoritis pada sistem lubrikasi dalam kaitannya dengan waktu relubrikasi serta kuantitas lubrikasi pada bearing 7210. Berdasarkan data komparasi lifetime bearing dan dibandingkan dengan analisis preventive maintenance maka kesimpulan yang dihasilkan berupa target pemeliharaan bearing yang ditentukan dalam koridor preventive maintenance schedule. Tujuan penelitian dalam penulisan analisis kerusakan bearing 7210 pada torsion shaft ini adalah untuk mengetahui pengaruh lubrikasi pada lifetime bearing 7210 pada torsion shaft, dalam kaitannya dengan analisis teoritis dengan lifetime bearing secara standar. Dapat menyusun penjadwalan preventive maintenance untuk bidang lubrikasi, agar efisiensi kerja bearing dapat lebih optimal.

\section{TINJAUAN LITERATUR}

\section{Definisi Elemen Mesin.}

Komponen structural yang termasuk dalam komponen struktural antara lain chassis, bearing, poros, komponen pengencang (baut), seal, dan pelumas (lubrikasi), Komponen elemen transmisi Yang termasuk dalam komponen elemen transmisi antara lain roda gigi (gear), puli dan sabuk (pulley and belt), gerigi dan rantai (sprocket and chain), coupling, rem. Komponen control yang termasuk dalam komponen kontrol antara lain tombol, switch, indikator, sensor, aktuator (pneumatic and hydraulic system) [2].

\section{Klasifikasi Bearing}

Secara dasar bearing dapat diklasifikasikan berdasarkan arah beban dan berdasarkan konstruksi atau mekanismenya mengatasi gesekan. Berdasarkan arah beban yang bekerja pada bantalan, seperti ditunjukkan pada bearing dapat diklasifikasikan menjadi [3].

TABEL 1. Klasifikasi jenis dan kerja bearing [3].

Bantalan radial (radial bearing): menahan
beban dalam arah radial/tegak lurus sumbu
poros




\section{Kegagalan Bearing}

Yang dimaksud dengan kegagalan pada bearing adalah kondisi dimana sebuah komponen bearing gagal menjalankan fungsi kerjanya pada suatu unit konstruksi mesin yang sesuai dengan standar umur pakai yang telah ditentukan. Banyak hal yang mempengaruhi kondisi ini baik internal maupun eksternal dari bearing tersebut terjadi kondisi yang disebut bearing failure. Yang disebut terjadi kondisi dimana tingkat pelayanan suatu bantalan gelinding sudah tidak optimal (bearing failure). Analisa kegagalan bantalan gelinding (bearing) dapat didefinisikan sebagai langkah-langkah pemeriksaan atas komponen bantalan gelinding yang mengalami kegagalan untuk dicari penyebab kerusakannya. Pengumpulan data material komponen serta proses pengerjaannya akan banyak membantu dalam menemukan penyebab kegagalan. Sampel yang diambil sedapat mungkin bisa memberikan gambaran mengenai peristiwa kegagalan. Oleh karena itu lokasi pengambilan harus tepat, serta keadaannya harus sebaik mungkin.

\section{Teori Lubrikasi (lubrication fundamental)}

Pada dua benda yang saling bergerak akan selalu menghasilkan gesekan diantara permukaan yang saling bersentuhan, hal ini disebabkan karena adanya gaya gravitasi (g). besarnya gaya gesek adalah perkalian antara gaya normal $(\mathrm{N})$ dengan koefisien gesek $(\mu)$ pada benda tersebut. Setiap benda mempunyai nilai koefisien gesek yang berbeda-beda [4].

Secara umuum gesekan gelinding mempunyai nilai yang lebih kecil dibandingkan gesekan rolling, dikarenakan gesekan gelinding mempunyai titik sentuhan yang semakin kecil sehingga nilai koefisien semakin kecil [5].

\section{Viskositas}

Definisi viskositas adalah ukuran dari ketahanan suatu fluida yang sedang mengalami deformasi akibat tegangan geser atau tegangan tarik (share rate). Ada dua macam nilai viskositas yaitu viskositas absolut (viskositas dinamik) yang diukur dalam satuan centipoises (cP) dan viskositas kinematis yang diukur dalam satuan centistokes (cSt). Dalam konversi satuan nilai $1 \mathrm{cP}$ mempunyai nilai $100 \mathrm{cSt}$. Semakin encer suatu unsur maka nilai viskositas kinematisnya semakin kecil dan kebalikannya semakin kental suatu unsur maka nilai viskositas kinematisnya makin besar contoh air bernilai $1 \mathrm{cSt}$, dan madu bernilai $1000 \mathrm{cSt}$. Hukum viskositas menyatakan untuk laju perubahan bentuk sudut fluida yang tertentu maka tegangan geser berbanding lurus dengan viskositas yang tinggi dibandingkan dengan liquid yang lain seperti air. Faktor kesebandingan koefisien gesek $(\mu)$ disebut dengan viskositas fluida [6].

Pada dunia industri modern serta otomasi, dan berdasarkan tuntutan dasar konsumen dunia industri maka para produsen berusaha untuk melakukan tindakan efisien serta jaminan kelancaran layak produksi dengan melakukan upaya perubahan pola pikir yang akan menentukan pola tindakan efektif dan multifungsi yang dikenal dengan maintenance. Definisi pemeliharaan elemen mesin adalah metode yang digunakan oleh pelaku manufaktur untuk menjaga performa mesin. Hal ini dilakukan untuk menjamin agar alur produksi dikerjakan oleh mesin yang bekerja secara standar, sehingga mendapatkan efisiensi yang optimal [7].

\section{Preventive Maintenance}

Merupakan usaha untuk meminimalisir potensi masalah secara terjadwal. (Baik jadwal jangka pendek hingga jangka panjang). Beberapa perusahaan menerapkan pola maintenance ini dengan membentuk tim yang akan selalu melakukan proses kontrol setiap kurun waktu tertentu untuk melakukan pemeliharaan, tujuannya adalah untuk mendeteksi potensi masalah sebelum menjadi masalah yang akan merugikan proses produksi (break down time).

\section{Predictive Maintenance}

Merupakan tindak lanjut dari preventive maintenance dimana dalam pola maintenance ini seorang teknisi sudah dapat memprediksi berdasarkan analisa maupun pengalaman untuk 
melakukan penggantian komponen mesin. Hal ini ditujukan untuk meminimalisir potensi terjadinya break down time pada produksi yang akan merugikan perusahaan.

\section{METODE PENELITIAN}

Pada penelitian ini akan menggunakan metode eksperimental yang dilandaskan pada perhitungan teoritis. Diagram alir penelitian yang dilakukan dapat dilihat pada gambar 1 .

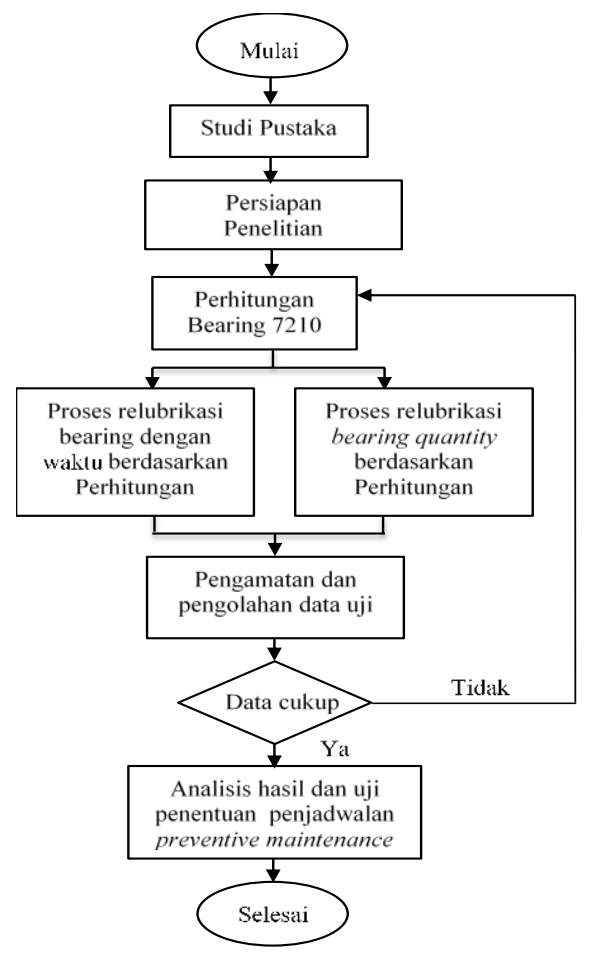

GAMBAR 1. Diagram alir penelitian.

Adapun pengamatan yang dilakukan adalah untuk mendapatkan data yang akan dijadikan acuan sebagai penjadwalan preventive maintenance terutama dalam pemeliharaan bearing 7210 pada torsion shaft. Berdasarkan diagram alir penelitian pada gambar 9 dapat dijabarkan bahwa pada penelitian ini dimuulai dari pembelajaran teoritis mengenai pemeliharaan bearing hingga prediksi umur pakai bearing serta menentukan skala pemeliharaan dalam hai ini adalah waktu relubrikasi dan banyak lubrikasi yang diberikan pada sebuah unit bearing.

Perhitungan secara teoritis pada bearing tipe 7210-B-XL-TVP dilakukan dengan berdasarkan referensi katalog untuk mendapatkan spesifikasi teknis bearing tersebut. Spesifikasi teknis inilah yang digunakan untuk menentukan pola relubrikasi ataupun kuantitas lubrikasi yang akan digunakan. Setelah penentuan waktu relubrikasi dan kuantitas lubrikasi ditentukan sehingga dapat dilakukan analisa perbandingan antara data aktual yang ada tentang penggunaan bearing 7210 ini dengan hasil perhitungan yang terjadi sehingga dapat ditentukan penyimpangan yang terjadi. Berdasarkan hasil perbandingan tersebut dilakukan suatu analisa lebih lanjut yang kemudian akan digunakan untuk menjadi landasan penentuan preventive maintenance serta penjadwalan penggantian bearing tersebut sebelum mengalami kerusakan yang menyebabkan produksi berhenti (down time).

\section{Pemasangan bearing pada unit torsion shaft}

Metode analisis yang akan dilakukan secara umum adalah membandingkan antara pola pemeliharaan bearing yang sudah dilakukan secara aktual sehari-hari dengan standar yang didapatkan dari hasil perhitungan teoritis. Sebelum menentukan analisis perhitungan 
secara teoritis maka perlu dilakukan pengambilan data standar yang didapatkan dari katalog bearing tersebut. Bentuk aktual bearing tipe 7210-B-XL-TVP tersebut dapat dilihat pada gambar 2 .

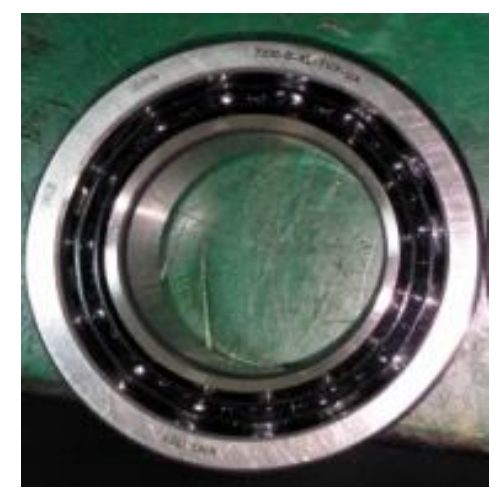

GAMBAR 2. Bearing tipe 7210

Pada penerapan penggunaan bearing ini diletakkan pada torsion shaft yang bekerja dengan mengalami beban radial serta beban aksial secara bersamaan seperti terlihat pada gambar 2.

TABEL 2. Spesifikasi teknis bearing 7210-B-XL-TVP [8].

\begin{tabular}{l}
\hline \\
\hline
\end{tabular}


Pembebanan radial yang terjadi berdasarkan berat pembebanan poros yang berputar dimana posisi bearing menahan beban dari berat komponen yang berhubungan dengan bearing tersebut. Sedangkan pembebanan radial yang terjadi adalah beban yang terjadi searah sumbu menuju bearing yang terpasang, hal ini berasal dari gaya dengan arah horizontal pada saat poros bekerja seperto terlihat pada gambar 3 .

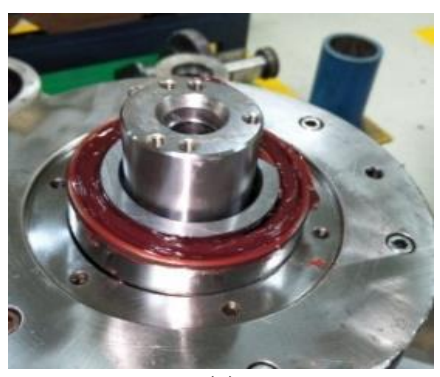

(a)

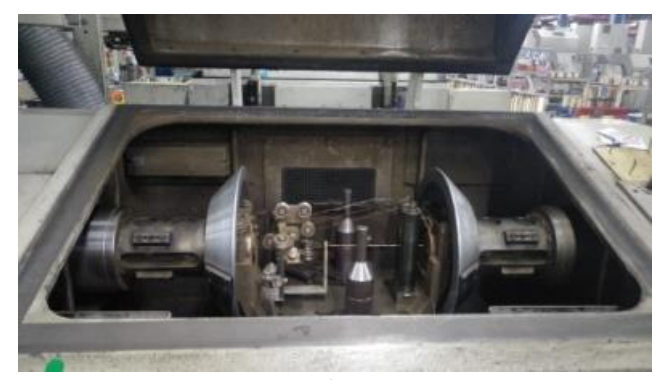

(b)

GAMBAR 3. (a) Pemasangan bearing 7210 pada torsion shaft, (b) Arah pembeban radial dan aksial

\section{Data spesifik bearing 7210-B-XL-TVP}

Berdasarkan penggunaan bearing standar yang digunakan pada mesin di bagian torsion shaft maka didapatkan tipe bearing yang digunakan yaitu bearing tipe 7210-B-XL-TVP. Dari tipe bearing yang terdapat pada gambar diatas maka didapatkan jenis spesifikasi bearing dengan data pada tabel 1 .

\section{Analisis Kerusakan}

Pada penilitian analisa kerusakan yang terjadi pada jenis bearing tipe 7210-B-XL-TVP dengan spesifikasi yang tertera pada tabel 1 dapat dijelaskan untuk kerusakan yang sering terjadi pada mesin bunching.

\section{HASIL DAN PEMBAHASAN}

\section{Menentukan umur pakai bearing $\left(\mathrm{L}_{\mathbf{H}}\right)$}

Untuk menentukan umur pakai bearing berdasarkan perhitungan dapat dilakukan dengan menggunakan formulasi sebagai berikut [8].

Diketahui :

$\mathrm{C}_{\mathrm{r}}$ standar $: 39000 \mathrm{~N}$

$\mathrm{C}_{0 \mathrm{r}}$ standar $: 28500 \mathrm{~N}$

$\mathrm{C}$ aktual $: 70 \mathrm{~kg}=686,7 \mathrm{~N}$ (data engineering maintenance)

$\mathrm{W}$ aktual $: 7.5 \mathrm{~kg}=73.575 \mathrm{~N}$ (data engineering maintenance)

n: $650 \mathrm{rpm}$ (data engineering maintenance)

Maka untuk menghitung rating usia ball bearing dapat dilakukan dengan persamaan (1).

$$
L=\left(\frac{\mathrm{c}}{\mathrm{w}}\right)^{3} \times 10^{6}
$$

$L=\left(\frac{686,7}{73,575}\right)^{3} \times 10^{6}=813,037=813,037 \times 10^{6}$ put

Untuk menghitung umur pakai ball bearing dapat dilakukan dengan formulasi persamaan (2)

$$
L_{H}=\frac{L}{60 . N} \text {. }
$$

$$
L_{H}=\frac{813,037 \times 10^{6}}{60 \times 650}=20,847 \text { jam } \approx 868 \text { hari } \approx 2,37 \text { tahun }
$$

Berdasarkan perhitungan di atas dapat disimpulkan bahwa secara perhitungan standar bearing 7210 yang dipasang pada torsion shaft maka dengan pembebanan radial $\mathrm{C}=70$ 
$\mathrm{kg}$ dan pembebanan aksial $\mathrm{W}=7.5 \mathrm{~kg}$ didapatkan umur pakai bearing selama $\mathrm{L}_{\mathrm{H}}=2.37$ tahun.

\section{Menentukan kekuatan dan tekanan bearing 7210}

Untuk menentukan kekuatan, tekanan dan rentan waktu relubrikasi pada penggunaan bearing 7210 pada unit torsion shaft dapat ditentukan dengan formulasi seperti pada referensi [9].

Diketahui:

Inner diameter $\mathrm{d}: 50 \mathrm{~mm}$

Tebal bearing $\mathrm{B}=1: 20 \mathrm{~mm}$

C: $70 \mathrm{~kg}=686,7 \mathrm{~N}$

$\mathrm{W}: 7.5 \mathrm{~kg}=73.575 \mathrm{~N}$

n: $650 \mathrm{rpm}$

Menentukan nilai kekuatan bearing $(W)$

Untuk menentukan nilai pembebanan dapat menggunakan persamaan (3):

$$
W=w \times l
$$

$\mathrm{W}=7.5 \mathrm{~kg} \times 20=150 \mathrm{~kg}$

Berdasarkan perhitungan kekuatan bearing 7210 dapat disimpulkan kekuatan batas aman adalah $150 \mathrm{~kg}$.

\section{Menentukan nilai tekanan $(P)$}

Untuk menentukan nilai tekanan dapat menggunakan persamaan (4).

$$
P=\frac{w}{l d}
$$

$p=\frac{150 \mathrm{~kg}}{20 \mathrm{~mm} x 50 \mathrm{~mm}}=0.15 \mathrm{~kg} / \mathrm{mm}^{2}$

Berdasarkan perhitungan tekanan bearing 7210 dapat disimpulkan tekanan batas aman adalah $0.15 \mathrm{~kg} / \mathrm{mm}^{2}$.

Menentukan masa relubrikasi $\left(\mathbf{t}_{\mathrm{fR}}\right)$

Untuk menentukan nilai relubrikasi bearing dapat ditentukan sebagai berikut:

Diketahui :

Inner diameter d :50 mm

Outer diameter D : $90 \mathrm{~mm}$

Tebal bearing $\mathrm{B}=1: 20 \mathrm{~mm}$

$\mathrm{C}_{0} \quad: \quad 70 \mathrm{~kg}=686.7 \mathrm{~N}$

$\mathrm{P}: \quad: 7.5 \mathrm{~kg}: 73.575 \mathrm{~N}$

$\mathrm{N}:: 650 \mathrm{rpm}$

$\mathrm{t}_{\mathrm{f}} \quad: 40.000$

Dari hasil keterangan diatas dapat dilakukan persamaan (5)

$$
\mathrm{t}_{\mathrm{fR}}=0.5 \times \mathrm{t}_{\mathrm{fG}} \text {. }
$$

Dimana :

$t_{f G}$ : Penentuan masa operasi grease belum diketahui maka dapat dilakukan penyelesaian dengan persamaan (6)

$$
\mathrm{t}_{\mathrm{fG}}=\mathrm{t}_{\mathrm{f}} \times \mathrm{k}_{\mathrm{T}} \times \mathrm{k}_{\mathrm{p}} \times \mathrm{k}_{\mathrm{R}} \times \mathrm{k}_{\mathrm{U}} \times \mathrm{k}_{\mathrm{s}}
$$

\section{Menentukan dasar masa operasi grease $\left(t_{f}\right)$}

Untuk menentukan dasar masa operasi grease dapat dijelaskan bahwa nilai dasar operasi grease pada data engineering adalah 40.000 jam dan untuk menentukan Specific Speed Parameter dapat ditentukan dengan persamaan (7).

$$
\text { Specific Speed Parameter }=\mathrm{k}_{\mathrm{f}} \times \mathrm{n} \times \mathrm{d}_{\mathrm{m}}
$$


$\mathrm{dm}=\frac{50+90}{2}=70 \mathrm{~mm}$

Specific Speed Parameter $=1.6 \times 650 \times 70=72.800 \mathrm{rpm}$

Menentukan faktor temperatur $\left(\mathbf{K}_{\mathrm{T}}\right)$

Penentukan nilai aktual temperatur kerja mesin yang didapat dari data engineering adalah $50{ }^{\circ} \mathrm{C}$, maka berdasarkan grafik $\mathrm{K}_{\mathrm{T}}$ yang di dapat dari data engineering adalah 0.1.

Menentukan nilai faktor beban (Kp)

Penentuan nilai faktor beban dan mengunakan pesamaan (8)

$$
\mathrm{C}_{0} \mathrm{P}=\frac{\mathrm{C}_{\mathrm{o}}}{\mathrm{P}}
$$

$\mathrm{C}_{0} \mathrm{P}=\frac{686,7}{73_{0}, 575}=9,33$

\section{Menentukan nilai osilasi $\left(K_{R}\right)$}

Berdasarkan hasil katalog bearing 7210-B-TVP adalah angular contact ball bearing (double row) maka di dapat nilai osilasi $\alpha=40^{\circ}$.

Menentukan nilai faktor lingkungan $\left(\mathrm{K}_{\mathrm{U}}\right)$

Berdasarkan nilai faktor dari engineering maintenance, kerja mesin torsion shaft termaksud dalam kategori kerja tingkat pembebanan menengah (moderate). Sehingga nilai faktor lingkungan $\left(\mathrm{K}_{\mathrm{U}}\right)$ dapat di tentukan berdasarkan tabel 3 .

TABEL 3. Tabel faktor lingkungan [9].

\begin{tabular}{|l|l|}
\hline Pengaruh lingkungan & Faktor $\mathbf{K}_{\mathbf{U}}$ \\
\hline Sedikit (slight) & 1 \\
\hline Menengah (moderate) & 0.8 \\
\hline Berat (heavy) & 0.5 \\
\hline
\end{tabular}

\section{Menentukan faktor pengaturan pada poros (KS)}

Pada penelitian ini yang dimaksud dengan pengaturan poros adalah posisi poros tempat bearing bekerja mengarah vertikal atau horizontal. Maka untuk menentukan faktor pengaturan pada poros (KS) dapat dilihat berdasarkan tabel 4 [10].

TABEL 4. Tabel faktor pengaturan pada poros [10].

\begin{tabular}{|l|c|}
\hline \multicolumn{1}{|c|}{ Pengaturan Poros } & Faktor $\mathbf{K}_{\mathbf{S}}$ \\
\hline Vertikal & $0.5-0.7$ \\
\hline Pengaturan lainnya & 1 \\
\hline
\end{tabular}

Setelah perhitungan relubrikasi terselesaikan maka dapat di hitung relubrikasi yang didapat pada persamaan dapat dilakukan penyelesaian dengan persamaan (9) dan (10)

$$
\begin{array}{r}
\mathrm{t}_{\mathrm{fG}}=\mathrm{t}_{\mathrm{f}} \times \mathrm{k}_{\mathrm{T}} \times \mathrm{k}_{\mathrm{p}} \times \mathrm{k}_{\mathrm{R}} \times \mathrm{k}_{\mathrm{U}} \times \mathrm{k}_{\mathrm{s}} . \\
\mathrm{t}_{\mathrm{fG}}=40.000 \times 0.1 \times 0.85 \times 0.45 \times 0.8 \times 1=1224 \mathrm{jam} \\
\mathrm{t}_{\mathrm{fR}}=0.5 \times \mathrm{t}_{\mathrm{Fg}}
\end{array}
$$

$\mathrm{t}_{\mathrm{fR}}=0.5 \times 1224=612 \mathrm{jam}$

Jadi dapat disimpulkan bahwa relubrikasi secara analisa teoritis adalah 612 jam $=25.5$ hari

\section{Menentukan kuantitas grease pada bearing}

Setelah menentukan waktu relubrikasi tahapan selanjutnya adalah menentukan kuantitas / jumlah pelumas tipe grease yang harus ditambahkan di setiap kali relubrikasi. Untuk menentukan kuantitas relubrikasi dapat ditentukan dengan tahapan menggunakan persamaan (11).

Diketahui :

$\mathrm{D}: 90 \mathrm{~mm}$

B : $20 \mathrm{~mm}$ 
Formulasi kuantitas grease persamaan (11) adalah:

$$
\mathrm{Q}=0,005 \times \mathrm{D} \times \mathrm{B}
$$

$Q=0,005 \times 90 \times 20=9 \mathrm{~g}$

Berdasarkan perhitungan kuantitas grease diatas dapat diketahui bahwa jumlah grease yang harus diberikan pada saat relubrikasi secara standar adalah sebanyak 9 gram yang dioleskan merata di sekeliling permukaan bearing.

\section{Komparasi analisis teoritis dengan aktual di lapangan}

Pada penelitian ini akan dibandingkan analisis teoritis terhadap aktual yang terjadi di lapangan tentang umur pakai bearing ${ }^{[11]}$. Adapun komparasi antara analisis hasil perhitungan teoritis dengan aktual dilapangan dapat dilihat pada tabel 5 .

TABEL 5. Komparasi antara kondisi aktual dengan hasil analisis teoritis

\begin{tabular}{|c|c|c|c|}
\hline Bearing 7210 & Relubrikasi & Kuantitas grease & Umur bearing \\
\hline Kondisi aktual & $3000 \mathrm{jam}$ & 30 gram & 657 hari $\approx_{1.8}$ th \\
\hline Analisis teoritis & $612 \mathrm{Jam}$ & 9 gram & 868 hari $\approx 2.37$ th \\
\hline Deviasi & $-2388 \mathrm{jam}$ & +21 gram & -0.57 tahun \\
\hline
\end{tabular}

Berdasarkan data diatas dapat dilihat dengan jelas komparasi antara kondisi aktual dengan analisis teoritis terjadi penyimpangan (deviasi) pada proses lubrikasi sebanyak 2388 jam sehingga terjadi kerusakan di bawah standar sebesar 0.57 tahun atau 211 hari lebih cepat dibawah standar.

\section{Standarisasi preventive maintenance}

Berdasarkan data perbandingan diatas maka dapat dibuatkan penjadwalan preventive maintenance untuk pemeliharaan bearing 7210-B-XL-TVP pada unit torsion shaft pada mesin bounching di salah satu PT. X. Adapun jadwal preventive maintenance yang diajukan seperti terliaht pada tabel 6 .

TABEL 6. Penjadwalan preventive maintenance bearing 7210-B-XL-TVP.

\begin{tabular}{|c|c|l|c|c|c|}
\hline Barang & $\begin{array}{c}\text { Maksimal batas } \\
\text { pemakaian }\end{array}$ & Basis data & $\begin{array}{c}\text { Faktor } \\
\text { aman }\end{array}$ & $\begin{array}{c}\text { Perubahan } \\
\text { Bagian }\end{array}$ & $\begin{array}{c}\text { Pemeliharaan dan } \\
\text { Pencegahan }\end{array}$ \\
\hline $\begin{array}{c}\text { Bearing } \\
7210\end{array}$ & 868 hari & $\begin{array}{l}\text { Analisis } \\
\text { teoritis }\end{array}$ & $24,3 \%$ & Hari ke 657 & $\begin{array}{l}\text { Setiap 612 jam per } 9 \mathrm{gr} \\
\text { lubrikasi }\end{array}$ \\
\hline
\end{tabular}

\section{KESIMPULAN}

Berdasarkan analisis yang telah dilakukan pada penelitian kerusakan bearing 7210 pada torsion shaft di atas maka dapat di simpulkan beberapa data yang akan dijadikan referensi bagi pembuatan jadwal preventive maintenance, diantaranya data kondisi aktual bearing 7210-B-XL-TVP, relubrikasi yang dilakukan setiap \pm 3000 jam. Kuantitas grease yang di berikan setiap relubrikasi sebanyak 30gram tanpa mengunakan alat meter grease sehingga grease yang masuk ke dalam bearing berputar berat yang dapat mempengaruhi putaran pada torsion shaft. Umur pakai bearing yang selama ini terjadi pada kisaran 657 hari.

Berdasarkan perhitungan relubrikasi dilakukan setiap 612 jam kerja. Berdasarkan perhitungan kuantitas grease yang diberikan setiap relubrikasi adalah sebanyak 9 gram. Berdasarkan perhitungan standar umur pakai bearing yang dapat dicapai adalah sebanyak 868 hari $=2.37$ tahun, maka dapat disimpulkan pula pola preventive maintenance untuk bearing 7210-B-TVP di mesin bunching di PT. X dengan kriteria maximum life time (umur pakai) bearing 7210 adalah selama 868 hari, perhitungan life time bearing didapatkan berdasarkan perhitungan teoritis. Penyimpangan yang terjadi antara umur pakai teoritis dengan umur pakai aktual adalah sebesar $24.3 \%$ hal ini dijadikan referensi bagi teknisi untuk menentukan angka keamanan bagi umur pakai bearing pada unit 
torsion shaft. Perencanaan preventive maintenance dalam proses relubrikasi adalah setiap 612 jam dengan kuantitas lubrikasi 9 gram grease di setiap bearing. Penjadwalan relubrikasi harus menggunakan alat meter grease agar kuantitas grease yang masuk sesuai dengan perhitungan teoritis adalah 9 gram.

\section{DAFTAR PUSTAKA}

[1] Sularso. 1991. "Elemen Mesin”. PT. Pradinya Paramita. Jakarta.

[2] Dahmir Dahlan, Prof.Dr.Ir. 2012. "Elemen Mesin”. Penerbit: Citra Harta Prima. Jakarta.

[3] NN. " Rolling Bearings Technical Handbook". PSL. ISBN 80-88889-74-X

[4] Dedison Gasni, Syahrul Rahmat. 2017. "Menentukan Regime Pelumasan Pada Ball Bearing Dengan Menggunakan Kurva Stribeck". Jurnal METTEK Volume 3 No 1 (2017). Jurusan Teknik Mesin Universitas Andalas, Padang.

[5] Kurmi \& J.K. Gupta, R.S. 2005. "Machine Design”. Eurasia Publishing House. Ram Nagar. New Delhi.

[6] NN. " Catalog Rolling Bearing”. FAG.NN. 2010.” Catalogue Rolling Bearing”. FAG. Germany

[7] Milje, R. 2011. "Engineering Methodology for Selecting Condition Based Maintenance". Thesis. Faculty of Science and Technology-University of Stavanger, Norwegia.

[8] Radhi Maladzi, Toni Prahasto, dan Achmad Widodo. 2017. "Analisis Kerusakan Bantalan Gelinding Dengan Variasi Kecepatan Putar Berdasarkan Pola Getaran Menggunakan Metoda Envelope Analysis". Jurnal Teknik Mesin, Vol. 5, No. 1, Tahun 2017. Fakultas Teknik, Universitas Diponegoro, Semarang.

[9] Hochmann D, Bechhoefer E. 2005. "Envelope bearing analysis": Theory and practice. In: IEEE Aerospace Conference Proceedings.

[10] White, M.F. 1979. "Rolling element bearing, vibration transfer characteristics: Effect of Stiffness", Journal Applied Mechanics, 46, 677-684 (1979).

[11] Suhardjono. 2004. "Analisis Sinyal Getaran untuk Menentukan Jenis dan Tingkat Kerusakan Bantalan Bola (Ball Bearing)". JURNAL TEKNIK MESIN Vol. 6, No. 2, Oktober 2004. Jurusan Teknik Mesin, Institut Teknologi Sepuluh Nopember, Surabaya. 